\title{
Editorial. Enterprising Differently: Markets, Policy Contexts And Social Enterprises
}

\author{
Mihaela LAMBRU \\ University of Bucharest
}

Having as a stat point the importance of this new field of analysis for the social sciences,

The Social Research International Review of (IRSR) launches a special issue on social enterprises. This special issue of IRSR aims to bring toghether contributions dealing with the trends of development of social enterprises in different societal and organisational contexts.

Over the last three decades, social enterprises (co-operatives, mutual organisations, associations and foundations) have raised the interest of both policy makers and scholars from different disciplines concerning the capacity of such initiatives to deal in an innovative way with current problems and challenges, which have a strong impact upon society, including social exclusion, sustainable economic and social local development, social services development.

Despite the existence in the international literature of a multitude of definitions of the social enterprise, a growing convergence in meaning has emerged in Europe, where the concept of social enterprise is more and more used to identify a 'different way' of doing business that occurs when institutional structures are created in order to pursue specifically social goals. An important contribution in realizing this convergence is due to specialized research networks such as EMES - European Research Network, which created the needed frame for comparative research

e-mail:1mb_ro@yahoo.com. 
related to experiences developed in various European countries as well as to coagulate the conclusions of these analyses into a set of criteria and specific indexes able to identify and to describe the social enterprises. Flexible and comprehensive, the EMES approach inspires more and more national initiatives from European countries to develop sustainable politics and to promote social enterprises.

Social enterprises can be seen as private, not-for-profit, autonomous institutions supplying goods and services of general interest. Specific for the social enterprises is the type of goods and services they supply to the community, as well as the type of production and allocation processes they provide for vulnerable groups.

The present economic crises made more visible the limited capacity of traditional capitalist enterprises and classical institutional arrangements aiming to tackle the issue of social exclusion in Europe. In many countries, public authorities are looking to the social enterprises as a solution or as a valid option for promoting social integration, economic growth and social justice for large categories of citizens at risk of financial, economic and social exclusion. Also, this growing interest for social enterprises has stimulated the research in this sector from different disciplinary perspectives (sociology, economy, policy studies, economic anthropology etc) and in different national context and by doing this, it is increasing the visibility and the degree of comprehensibility of the sector.

The attractiveness of social enterprises is confirmed by the large number of new legal frameworks and support policies aimed to recognize its specificity and to regulate this type of enterprise, that have been recently introduced-or are in the process of being discussed - in different EU countries (e.g. Italy; UK; France; Slovenia; Poland, etc.). The research made operational and visible the existence of some legislative models concerning social enterprises in Europe. No matter we are talking about 'open law format' or 'cooperative model' or 'company model', the social enterprise starts to find in every European countries a juridical and institutional framework which variations are due to historical traditions, welfare roots as well as socio-economic conditions.

In the same time, we have witnessed an increased interest with regard to social enterprises for policy network development, policy advocacy, strategic communication, and evaluation methodologies. With an outstanding research experience in social enterprises field, Carlo Borzaga and Giulia Galera are offering a review of the concept and of the practice of social Enterprises in Europe. By accomplishing a remarkable synthesis of the results of recent researches in social enterprises field, the authors stated out the fact that social enterprises are a well consolidated structural trend. The issue offers a detailed analysis concerning the enabling conditions to develop a comprehensive policy framework for social enterprises in different European countries. Having as a starting point the understanding of the trend differences concerning the development of social enterprises, the authors formulate a comprehensive classification of different types of policy practices in European countries. According to the authors, social 
enterprises can be classified by the degree of institutionalization they achieved. The first category includes countries where a legal and political recognition of social enterprises exists. A second category includes countries where there is an indirect recognition of social enterprises, where these enterprises are part of the politicoadministrative rhetoric, but they are not yet integrated into the policy practice. The third category is represented by those countries where one can find an isolated emergence of social enterprises in an institutional and legal context which is often unfavorable. At the end of their review, the authors introduce the success story concerning the development of public politics with regard to the social enterprises support in Italy, emphasizing on the exogenous and endogenous conditions of a successful policy reform in this field.

Cristina Parente, Monica Santos, Vanessa Marcos, Luisa Veloso and Daniel Costa are focusing their attention on the concept of social entrepreneurship. Their article explores the different perspectives on social entrepreneurship in Portugal using a qualitative methodological approach. Through analysis of interviews with key actors operating within the third sector, the authors are triying to understand the place of the social entrepreneurship concept within the third sector organization practice, how a specific understanding of the concept by the third sector key actors is shaping their actions.

Darina Zaimova, Evgeni Genchev, and Hristo Momchilov review aims at describing the profile of the third sector organizations in Bulgaria, the practice of social contracting and also to assess the impact of their work in social services field. Having as a starting point the analysis of social contracting practice between NGOs and the central public authorities, the authors are analyzing the characteristics of the welfare mix system in Bulgaria. Their review is organized into three parts. The first one aims to outline the key actors involved in the distribution and the use of public spending. The second part concentrates on the legal framework which regulates the relationships in the management, the implementation, the control and the potential beneficiaries of the social programs. The third part generalizes the results of the stochastic frontier analysis applied. The panel data model contains information about the expenditures related to each social program, included here as a decisionmaking unit. Having as a starting point this analysis, the influence of certain institutional factors to the efficiency of the operational programs is identified.

Ioannis Nasioulas' review introduces the historic as well as the recent development related to social economy and social entrepreneurship in Greece. The author reviews in details the juridical and institutional frame for the social enterprises by pointing out the elements related to the historical aspect of the evolution of the legal framework and by making detailed comments of the new legislative framework for the social economy. For the first time, the new legislation concerning the social cooperatives, recently adopted in Greece, introduces at a public politics level the concept of a social economy. Inspired by the Italian model, this new type of cooperative is defined by the law as one that has social aims and entrepreneurial 
means in order to bring them to life. Along with the 'old cooperatives', the Limited Liability Social Cooperatives, this new type of social cooperative creates new opportunities to face the challenges related to the development of complex social services and is asked to complementary act with the nonfor-profit organizations. 